\title{
GLOBAL VALUES FOR LOCAL RESOURCES: A CONTINGENT VALUATION APPROACH FOR SINHARAJA RAIN FOREST RESERVE IN SRI LANKA
}

\author{
U A D Prasanthi Gunawardena and G Edwards-Jones \\ University of Sri Jayewardenepura, Nugegoda. \\ University of Wales, Bangor.
}

Tropical forests are sources of important global use and non-use values. However, these values are not often reflected in global markets, thus creating global externalities. In order to demonstrate global values of tropical rain forests, this study sought to estimate global non-use values of the Sinharaja Rain Forest Reserve in Sri Lanka

A contingent valuation survey was carried out in the United Kingdom in order to obtain existence and bequest values for the forest. Open ended questions were asked from the selected sample of respondents to obtain their maximum willingness to pay.

The non use values elicited for the forest were related to variation in respondents' socio economic status. Multiple regression analysis showed that income and education had positive coefficients for both existence and bequest values.

The results showed that remote populations have positive values for tropical rain forest. The implications of these results to the use of contingent valuation methodology for estimating total economic values of forests in developing countries is discussed, and the particular implications of demonstrating the magnitude of extermal benefits that could provide insights into the correction of global economic failures highlighted. 